\title{
Framework Literasi Kelautan Sebagai Acuan Pembelajaran Sains di Negara Maritim
}

\author{
Bony Irawan \\ Jurusan Pendidikan Biologi, Universitas Maritim Raja Ali Haji, Indonesia \\ Pengiriman: 2 Maret 2018; Diterima: 12 Maret 2018; Publikasi: Maret 2018
}

\begin{abstract}
Recent shift into maritime based dvelopment in Indonesia must be supported by an education system that performs its function in educating future citizens. Every sudents must be educated systematically at school to have good ocean literacy. Up until now, ocean literacy is not a focus and only gets a small portion on the national education curriculum. As a result, Indonesian students do not have positive knowledge, attitudes, and perception of the sea. The prevailing curriculum standards in Indonesia do not have specific subjects about maritime science. Therefore, important knowledge about the sea must be integrated into related subjects, i.e. biology. A framework is needed to guide biology teachers to integrate essential ocean literacy in to their leassons. In this theoretical review, author discusses a framework of ocean literacy that contains essential knowledge that students must master at a high school level. The ocean literacy framework proposed by COSEE are enriched by local content for better practicality in Indonesian classroom. The ocean literacy Framework is formulated with the international standards of ocean literacy in mind, taking into account the local conditions and wisdom of Indonesia. This Framework summarizes the essential ocean related knowledge to be integrated into related learning at school. In addition, this framework can also be used as a reference by the management of aquariums and parks, science parks, and other informal information centers. It is hoped that this framework can facilitate teacher's tasks in integrating ocean literacy into their lesson plans..
\end{abstract}

\section{Keywords: Marine literacy, Framework, standard content, marine biology education}

\begin{abstract}
ABSTRAK: Pembangunan kemaritiman nasional yang sedang digalang di Indonesia harus didukung oleh sistem pendidikan yang menjalankan fungsinya dalam mendidik calon warga negara. Agar pembangunan kemaritiman itu berhasil, siswa harus dididik secara sistematis pada bangku sekolah untuk memiliki literasi kelautan yang baik. Selama ini pengetahuan tentang kelautan tidak menjadi fokus dan hanya mendapat porsi kecil pada kurikulum pendidikan nasional. Akibatnya siswa Indonesia tidak memiliki pengetahuan, sikap, dan persepsi yang positif terhadap laut. Standar kurikulum yang berlaku di Indonesia tidak memiliki mata pelajaran khusus tentang ilmu kelautan. Materi dan pengetahuan penting tentang laut yang harus dimiliki calon warga negara ini dapat diintegrasikan kedalam mata pelajaran terkait, terutama biologi. Agar integrasi ini berjalan baik, diperlukan adanya standar isi pengetahuan kelautan yang dapat diacu oleh guru dalam mengembangkan prses pembelajaran. Penulis merumuskan sebuah framework literasi kelautan yang memuat pengetahuan esensial yang harus dikuasai siswa pada jenjang sekolah menengah. Framework literasi kelautan ini dirumuskan dengan mempertimbangkan standar ocean literacy yang berlaku secara internasional, dengan memperhatikan kondisi dan kearifan lokal Indonesia Framework ini merangkum wawasan kelautan yang esensial untuk diintegrasikan kedalam pembelajaran yang terkait di sekolah. Selain itu framework ini juga dapat dijadikan acuan oleh pengelola akuarium dan taman, science park, dan pusat informasi informal lain. Diharapkan framework ini dapat memudahkan tugas guru dalam mengintegrasikan pengetahuan kelautan kedalam pembelajaran.
\end{abstract}

Kata Kunci: Literasi Kelautan, Framework, Standar isi, pendidikan biologi kelautan

*Penulis Korespondensi:

Alamat surel: bony@umrah.ac.id 


\section{PENDAHULUAN}

Reorientasi pembangunan nasional berbasis kemaritiman yang sedang gencar digalakkan pemerintah saat ini dapat dipandang sebagai sebuah perubahan yang strategis. Sudah seharusnya sebuah negara kepulauan untuk membangun dan mensejahterakan rakyatnya melalui sumberdaya laut yang dimilikinya. Pembangunan kemaritiman merupakan konsep yang holistik meliputi pembangunan sarana prasarana, teknologi, paket kebijakan, sampai pada konservasi dan perlindungan biodiversitas laut. Agar pembangunan ini berhasil dengan baik, mutlak diperlukan warga negara yang punya pengetahuan, sikap, dan persepsi yang benar terhadap laut. Sistem pendidikan adalah satu-satunya sarana sistematis, terukur, dan reliabel yang berperan mencetak lulusan yang cerdas, kompeten, dan memiliki literasi yang memadai untuk dapat hidup mandiri sebagai warga negara dan warga dunia. OECD memaklumatkan bahwa suatu

Sistem pendidikan harus mendukung arah pembangunan suatu bangsa (OECD, 2013). Terdapat suatu tingkat literasi minimum harus dimiliki masyarakat agar program pembangunan dapat terlaksana dan paket kebijakan kemaritiman tersebut mendapat dukungan dari masyarakat. Kesadaran akan pentingnya pengetahuan dasar kelautan telah muncul di Amerika Serikat, Jepang, Kanada, Belgia, dan beberapa negara lain sejak dua dekade lalu. Sekarang gerakan ini terwujud dalam bentuk kampanye literasi kelautan dengan tujuan untuk mendidik warga dunia yang bersahabat dengan laut.

Permasalahan di Indonesia adalah selama ini pengetahuan tentang laut tidak menjadi fokus dan tidak mendapat porsi yang cukup dalam kurikulum pendidikan sekolah. Tidak ada mata pelajaran yang dirancang khusus untuk membahas tentang pengetahuan kelautan. Kepingan kecil materi yang menunjang literasi kelautan tersebar pada mata pelajaranpelajaran yang bersinggungan, terutama biologi dan geografi. Namun keberadaannya tidak disengaja, tidak eksplisit dan sistematis. Sehingga dapat dikatakan warga negara Indonesia tidak pernah mendapatkan pembekalan tentang kelautan selama mengikuti pendidikan di bangku sekolah. Maka tidak heran apabila siswa dan masyarakat luas di Indonesia tidak memiliki pengetahuan dan kecintaan terhadap laut. Akibatnya, pembangunan kemaritiman yang dicita-citakan akan sulit mendapat dukungan dari masyarakat yang apatis sehingga sulit untuk terlaksana.

Solusi dari permasalahan tersebut membutuhkan perombakan besar-besaran pada kurikulum. Disisi lain, lembaga pendidikan tenaga kependidikan (LPTK) yang bertugas mendidik calon guru juga harus mempersiapkan lulusan yang memiliki literasi kelautan yang baik. Sehingga pada gilirannya para guru ini dapat menjadi penggerak kemajuan dari kelas-kelas yang mereka ajar kelak. Apabila tidak terdapat mata pelajaran khusus yang membahas tentang pengetahuan kelautan, maka upaya peningkatan literasi kelautan dapat dilakukan melalui mata pelajaran terkait seperti biologi dan geografi (Cudaback, 2008). Kurikulum yang berlaku dalam sistem pendidikan Indonesia tidak memuat mata pelajaran pengetahuan kelautan. Oleh karena itu usaha peningkatan literasi kelautan siswa harus dilakukan melalui mata pelajaran lain yang memiliki irisan, terutama biologi. untuk itu diperlukan adanya pedoman yang memuat konsep-konsep dasar literasi kelautan yang dapat diacu oleh guru. Penelitian ini bertujuan untuk mengembangkan framework literasi kelautan yang sesuai untuk digunakan di sekolahsekolah.

\section{METODE PENELITIAN}

Penelitian ini merupakan perumusan sebuah framework yang mengadopsi prinsip Research and Development. Tahap awal adalah studi pustaka mengumpulkan body of knowledge terkait pengetahuan kelautan yang penting bagi manusia abad 21. Sumber utama telaah ini adalah konten literasi kelautan yang dirilis 
oleh COSEE bersama lembaga studi kelautan lainnya pada 2005. Body of knowledge dari studi pustaka ini diperkaya dengan konten khazanah asli yang digali dari kearifan lokal. Keseluruhan wawasan tentang kelautan ini kemudian diterjemahkan menjadi poin-poin yang yang dapat diaplikasikan kedalam pembelajaran di mata pelajaran yang terkait.

\section{HASIL DAN PEMBAHASAN}

Berdasarkan hasil telahaan, maka dirancang framework literasi kelautan yang dapat dijadikan pedoman wawasan kelautan bagi pendidikan dasar sebagai berikut.

\section{Lautan di bumi merupakan satu kesatuan yang memiliki banyak karakteristik}

a. Lautan adalah ciri fisik utama dari planet bumi, dengan luas tutupan sekitar $70 \%$ dari total permukaan bumi. Indonesia juga merupakan sebuah negara kelautan yang terdiri atas 17.000 lebih pulau dengan $70 \%$ luas wilayah terdiri atas lautan.

b. Cekung lautan terdiri dari dasar laut dan seluruh ciri geologinya (pulau, lubuk, palung, celah, dan lembah laut) dengan ukuran yang bervariasi dibawah pengaruh pergerakan lempeng bumi. Puncak tertinggi, lembah terdalam, dan dataran terluas di dunia semua ada di lautan.

c. Nusantara memiliki bentang alam lautan yang variatif mulai dari estuari, gunung api aktif di dasar laut sampai palung dan lubuk laut yang terdalam.

d. Lautan di bumi terhubung oleh sistem sirkulasi yang salin terinterkoneksi yang disebabkan oleh energi angin, pasang surut, efek koriolis, matahari, dan perbedaan kerapatan air. Bentuk cekung lautan dan posisi daratan disekitarnya akan mempengaruhi alur sirkulasi laut. Arus laut global ini menyebabkan perpindahan energi, materi, dan organisme diantara lautan di bumi. Perubahan sirkulasi di lautan menyebabkan perubahan besar pada ekosistem dan mempengaruhi iklim.

e. Posisi Indonesia di khatulistiwa dan berada diantara samudra india dan pasifik menjadikan Indonesia memiliki iklim tropis dengan curah hujan yang relatif tinggi serta terpengaruh oleh dinamika iklim seperti la nina dan el nino.

f. Permukaan laut adalah ketinggian ratarata air laut terhadap daratan dengan memperhitungkan pengaruh pasang surut. Permukaan laut dapat berubah seiring geraan lempeng tektonik yang merubah ketinggia dasar laut dan daratan berubah. Pembekuan dan pelelehan es di kutub juga mempengaruhi ketinggian permukaan laut. Pengaruh suhu juga menyebabkan perubahan permukaan laut.

g. Sebagian besar cadangan air yang dimiliki bumi terletak di lautan. Air laut bersifat asin, titik beku sedikit lebih rendah dari air tawar, kerapatan sedikit lebih tinggi, konduktifitas listrik jauh lebih tinggi, dan sedikit basa. Keseimbangan $\mathrm{Ph}$ sangat penting untuk kehidupan di lautan, sekaligus menjaga laju penyerapan $\mathrm{CO}$ di atmosfer.

h. Lautan adalah bagian tak terpisahkan dari siklus air dan saling terhubung dengan semua cadangan air yang ada di bumi melalui proses evaporasi dan presipitasi.

i. Lautan terhubung ke semua danaudanau besar, badan air, dan sungai karena semua aliran air bermuara ke lautan. Sungai dan aliran air akan membawa sedimen dan nutrisi ke estuari dan pesisir, lalu ke lautan.

j. Meskipun lautan sangatlah luas, tapi ia memiliki batasan, dan sumberdaya yang dimilikinya juga terbatas. Oleh karena itu, segala bentuk eksploitasi harus dilakukan dengan terkontrol dan seimbang.

k. Ekosistem lautan memiliki Lautan bukanlah tempat pembuangan sampah dan limbah yang aman 


\section{Lautan dan kehidupan didalamnya membentuk karateristik bumi}

a. Sebagian besar material penting di bumi, dan daur biogeokimia bersumber dari lautan. Aktifitas geologi seperti pembentukan batuan sedimen, silikat, dan karbonat banyak terjadi di lautan.

b. Perubahan ketinggian permukaan laut yang berlangsung terus menerus mempengaruhi ukuran dan bentuk lempeng benua, membentuk dan merubah laut pedalaman, dan mempengaruhi bentuk daratan.

c. Erosi terjadi di wilayah pantai disebabkan oleh aktifitas angin, ombak, arus sungai dan laut, dan proses pergerakan lempeng tektonik yang menggerakkan sedimen. Pasir pantai merupakan hasil erosi yang terbawa oleh aliran air ke wilayah pesisir. Penyebarannya dipengaruhi oleh aktifitas pasang, ombak, dan angin.

d. Lautan adalah tempat penyimpanan cadangan karbon bumi yang didaur dalam siklus karbon. Semua makhluk hidup di bumi membutuhkan karbon sebagai penyusun tubuhnya..

e. Aktifitas tektonik, perubahan ketinggian permukaan air laut, dan efek gelombang mempengaruhi struktur fisik dan bentuk daratan di daerah pesisir.

\section{Lautan adalah faktor utama penentu cuaca dan iklim}

a. Interaksi antara proses-proses yang terjadi di lautan dan di samudera merupakan pengontrol cuaca dan iklim.

b. Lautan meupakan mediator cuaca dan iklim global yang menyerap sebagian besar energi matahari yang diterima bumi. Pertukaran energi panas antara lautan dan atmosfer merupakan sumber penggerak siklus air.

c. Pertukaran energi panas antara lautan dan atmosfer dapat mengakibatkan perubahan ekstrim pada pola cuaca global dan regional, yang menyebabkan hujan berkepanjangan atau kekeringan.
Gejala yang paling terkenal antara lain la nina dan el nino yang menyebabkan perubahan curah hujan dan kemarau panjang.

d. Kondensasi awan yang bersumber dari evaporasi di lautan tropis yang hangat merupakan sumber energi bagi topan dan badai. Hampir seluruh curah hujan yang jatuh di daratan bersumber dari lautan tropis.

e. Lautan memainkan peran utama dalam siklus karbon di bumi. Setengah dari produktivitas primer bumi dihasilkan dilautan. Lautan berperan menyerap setengah dari total jumlah karbondioksida dan metan yang ada di atmosfir.

f. Lautan merupakan faktor penentu perubahan iklim melalui mekanisme penyerapan, penyimpanan, dan perpindahan energi panas, air, dan karbon.

g. Perubahan yang terjadi pada sistem lautan-atmosfer dapat mempengaruhi keadaan iklim. Perubahan ini dapat membawa dampak yang dramatis secara fisik, kimiawi, biologis, ekonomi, dan sosial.

\section{Adanya lautan adalah alasan mengapa bumi dapat ditinggali}

a. Sebagian besar oksigen yang ada di atmosfer bumi bersumber dari hasil fotosintesis organisme yang hidup di laut. Akumulasi oksigen tersebut menciptakan komposisi udara atmosfer seperti sekarang, sehingga kehidupan dapat berkembang dan bertahan di darat.

b. Lautan adalah tempat partama kali munculnya kehidupan. Bukti bentuk kehidupan tertua ditemukan di lautan. Jutaan spesies makhluk hidup yang dijumpai sekarang berkembang dan berevolusi dari nenek moyang yang berasal dari lautan.

c. Lautan secara terus-menerus telah menyediakan suplai oksigen, air, dan nutrisi yang diperlukan untuk 
menunjang segala bentuk kehidupan yang ada di bumi.

\section{Lautan memiliki kekayaan biodiversitas dan ekosistem yang besar}

a. Bentuk kehidupan di laut terentang mulai dari mikroba yang paling kecil sampai hewan terbesar di bumi.

b. Sebagian besar biomassa makhluk hidup di laut terdiri dari mikroorganisme, yang berperan sebagai produsen utama jaring makanan di laut. Mikroorganisme memiliki laju pertumbuhan yang sangat cepat. Kelompok ini menyediakan oksigen dan karbon dalam jumlah besar bagi bumi.

c. Banyak kelompok makhluk hidup yang hanya ditemukan di laut. Biodiversitas lingkungan laut jauh lebih tinggi dibanding ekosistem terestrial.

d. Beberapa makhluk hidup laut menunjukkan contoh karakter unik dalam hal siklus hidup, adaptasi, dan pola interaksi eksklusif yang tidak ditemukan pada makhluk terestrial.

e. Lautan menyediakan ruang hidup yang luas dengan berbagai variasi ekosistem yang unik mulai dari permukaan laut, bertingkat sampai laut dalam, sampai dibawah dasar laut. Sebagian besar ruang hidup yang dimiliki bumi terdapat di laut.

f. Bentuk ekosistem laut ditentukan oleh faktor lingkungan dan komunitas makhluk hidup yang ada didalamnya. Kehidupan tidak tersebar merata di laut, karena adanya perbedaan faktor abiotik seperti kadar oksigen, salinitas, suhu, ph, cahaya, nutrisi, tekanan, substrat, dan sirkulasi. Ada bagian tertentu lautan yang menyokong kelimpahan makhluk hidup dalam jumlah yang besar, sementara terdapat bagian yang hanya ditempati sedikit organisme.

g. Di laut dalam terdapat ekosistem yang tidak bergantung pada cahaya matahari dan organisme fotosintesis. Ekosistem hydrothermal vents, mata air panas bawah laut, dan resapan metan dingin semuanya mengandalkan energi kimia dan organisme kemosintesis sebagai produsen.

h. Pasang, ombak, predasi, substratsi,dan faktor lain merupakan penentu zonasi vertikal di kawasan pantai. Di laut lepas, zonasi vertikal dipengaruhi oleh kerapatan, tekanan, dan intensitas cahaya. Pola zonasi ini mempengaruhi distribusi dan keberagaman organisme.

i. Estuari berperan sebagai daerah nurturasi yang penting dan produktif bagi hewan air dan hewan laut.

\section{Lautan dan manusia memiliki hubungan yang tidak terpisahkan}

a. Lautan memainkan peranan dalam kehidupan setiap manusia. Air dan oksigen yang dibutuhkan manusia disediakan oleh lautan. Lautan merupakan pelindung yang memoderasi cuaca dan iklim bumi.

b. Laut menyediakan sumber makanan, obat-obatan, mineral, dan energi yang dibutuhkan manusia. Lautan merupakan faktor penting dalam perekonomian dan transportasi serta keamanan nasional.

c. Lautan adalah sumber inspirasi, rekreasi, rejuvenasi, dan penemuan. Bagi beberapa suku bangsa, lautan merupakan bagian sentral dari peradaban mereka.

d. Manusia mempengaruhi lautan dengan berbagai kegiatan yang dilakukannya. Undang-undang, peraturan, dan manajemen sumberdaya yang berlaku akan mempengaruhi keadaan laut. Aktifitas manusia banyak melepaskan polutan yang mendegradasi kualitas lingkungan laut, merubah keadaan kimiawi laut, dan mengubah bentuk fisik lautan dan pesisir.

e. Perubahan suhu dan ph laut dapat mempengaruhi kelangsungan hidup banyak spesies, sehingga mempengaruhi keanekaragaman makhluk hidup di laut. 
f. Sebagian besar populasi bumi tinggal di daerah pesisir. Daerah pesisir memiliki kerawanan terhadap bencana alam seperti tsunami, badai, topan, perubahan ketinggian air laut, dan banjir.

g. Setiap manusia memiliki tanggungjawab untuk menjaga kelestarian laut. Lautan telah menopang kehidupan di bumi, dan manusia juga harus hidup dengan cara yang bersahabat dengan laut. Diperlukan tindakan individual dan kolektif untuk mengelola sumberdaya lautan untuk kebaikan bersama.

\section{Lautan masih belum banyak tereksplorasi}

a. Lautan merupakan daerah yang paling sedikit dijelajahi manusia. Baru sekitar $5 \%$ dari total wilayah lautan yang sudah diungkap. Peneliti dan penjelajah generasi mendatang berkesempatan untuk melakukan eksplorasi, diskoveri, dan inovasi tentang lautan.

b. Pemahaman yang baik akan laut bukan hanya sekadar perkara rasa ingin tahu. Laut teramat penting bagi kehidupan manusia, sehingga kelangsungan hidup umat manusia di masa depan akan sangat dipengaruhi oleh pemahaman manusia tentang laut dan segala proses yang terjadi didalamnya.

c. Dalam 50 tahun terakhir eksploitasi terhadap sumberdaya laut meningkat drastis. Kelestarian sumberdaya ini sangat bergantung pada pemahaman kita terhadap potensi sumberdaya tersebut.

d. Perkembangan Iptek modern mempermudah manusia dalam mengeksplorasi dan mengenal laut. Perkembangan teknologi sensor, buoy apung, instalasi pengamatan bawah laut, kapal selam mini, drone, dan satelit telah membuka cakrawala baru bagi ilmuwan.

e. Pengunaan model matematika merupakan instrumen penting dalam upaya memahami lautan sebagai sebuah sistem. Model matematika membantu kita untuk memahami kompleksitas sistem di lautan serta interaksinya dengan interior bumi, dengan atmosfer, iklim, dan daratan.

f. Eksplorasi laut menuntut penguasaan interdisiplin bidang ilmu. Kedepannya diperlukan kolaborasi antara ahli biologi, kimia, klimatologis, programer komputer, insinyur, ahli geologi, meteorologis, ahli fisika, ilustrator, dan animator. Kerjasama ini menghasilkan pemahaman dan ide-ide baru untuk memahami lautan.

\section{KESIMPULAN DAN SARAN}

Promosi literasi kelautan di Indonesia masih berada pada tahap awal. Studi kasus yang sama di negara Amerika Serikat pada tahap awal promosi literasi kelautan menunjukkan usaha awal yang perlu dilakukan adalah menyusun framework yang dapat diacu (strang \& Tudenham, 2005). Pada fase ini diperlukan sosialisasi yang lebih gencar ke sekolah dan guru-guru. Framework yang dikembangkan ini selanjutnya harus disosialisasikan kepada stakeholder untuk dapat diaplikasikan dan diacu dalam pembelajaran IPA dan biologi di sekolah.

\section{UCAPAN TERIMAKASIH}

Ucapan terimakasih disampaikan kepada Direktorat Riset dan Pengabdian Masyarakat Direktorat Jenderal Penguatan Riset dan Pengembangan, Kemenristekdikti yang telah memberikan dana Penelitian Dosen Pemula serta juga kepada semua pihak yang telah membantu terlaksananya penelitian ini.

\section{DAFTAR PUSTAKA}

[1] COSEE, National Geographic Society, NOAA, College of Exploration (2005). Ocean Literacy: The Essential Principle of Ocean Sciences Grades K-12, a jointly published brochure. 
[2] Cava F., S. Schoedeinger, C. Strang and P. Tuddenham. (2005). Science Content Standards for Ocean Literacy: A Report on Ocean Literacy.

[3] COSEE, National Geographic Society, NOAA, College of Exploration (2005). Ocean Literacy: The Essential Principle of Ocean Sciences Grades K-12, a jointly published brochure.

[4] Cudaback C. (2008). Ocean literacy, There's more to it than content. Oceanography Journal 21:10-11.

[5] OECD. (2013). PISA 2012 Results. OECD.

[6] Schoedinger S., L.U. Tran and L. Whitley. (2010). From the principles to the scope and sequence: A brief history of the ocean literacy campaign. NMEA Special Report

[7] Strang, C., Tuddenham, P. (2005). 10 years of Ocean Literacy in the USA and beyond: actions, results, reflections and discussion. The University of California Press. 